\title{
OS TERRITÓRIOS DO HOSPÍCIO E O DOMÍNIO DA LOUCURA NA IMAGINAÇÃO LITERÁRIA DE GUILLERMO ROSALES
}

\author{
THE TERRITORIES OF THE HOSPICE AND THE DOMAIN OF \\ MADNESS IN THE LITERARY IMAGINATION OF GUILLERMO \\ ROSALES
}

Isaque de Moura Gonçalves Neto ${ }^{1}$

\begin{abstract}
RESUMO
A trajetória biográfica do escritor cubano Guillermo Rosales é atravessada por um extenso histórico de violência, desajustes e frustrações. Perseguido por vozes e visões que o atormentavam, Rosales foi diagnosticado com esquizofrenia ainda durante a adolescência, tendo passado por diversas instituições psiquiátricas ao longo da vida. Parte dessas experiências estão expostas em sua obra de maior destaque, o romance Boarding Home, publicado originalmente em 1987. No livro, Rosales dá voz a seu alter ego, o protagonista William Figueras, escritor exilado da ilha de Cuba que narra sua rotina na condição de interno em um sanatório particular nos Estados Unidos. O personagem expõe os abusos, as situações precárias do hospício e as constantes agressões físicas e psicológicas às quais ele e outros pacientes são submetidos, descrevendo um cenário no qual os sujeitos tornam-se progressivamente despojados de individualidade. Assim, tomando como referência o espaço asilar do manicômio e seu contexto de aniquilação de subjetividades, este artigo busca refletir sobre as dinâmicas de deterioração identitária no mundo do internado e os processos de desfiguração pessoal aplicados ao regime de confinamento na home. Nessa perspectiva, mobilizam-se os pressupostos teóricos do sociólogo canadense Erving Goffman (1987), nas discussões acerca das instituições totais, e os principais mecanismos de mortificação associados a tais estabelecimentos. As análises foram realizadas com base na edição original do romance, publicada pela editora espanhola Siruela, em 2003. Argumenta-se que a Boarding Home, enquanto suposta casa de saúde mental, desvia-se gravemente de sua finalidade terapêutica, na medida em que os personagens incorporam e reproduzem a violência da estrutura institucional que os suplicia. Nessas circunstâncias, compreende-se que o espaço manicomial não opera como local de acolhimento ou cuidado, mas como engrenagem de opressão, abandono e extermínio de vidas humanas.
\end{abstract}

PALAVRAS-CHAVE: Boarding Home; Guillermo Rosales; Instituições totais; Literatura cubana.

\begin{abstract}
The biographical trajectory of the cuban writer Guillermo Rosales is transversed by an extensive history of violence, maladjustments and frustrations. Pursued by the voices and visions that plagued him, Rosales was diagnosed with schizophrenia during his adolescence, having gone to asylum institutions throughout his life. Part of these experiences are exposed in his most prominent work, the novel Boarding Home, originally published in 1987. In the book, Rosales gives voice to his alter ego, the character William Figueras, an exiled writer from the island of Cuba who narrates his routine in his condition intern in a private sanatorium in the United States. The character exposes the abuses, the precarious situations of the hospice and the constant physical and psychological agressions to wich he and other patients are subjected, describing a scenario in which the subjects become progressively stripped of individuality. Based on the asylum space and
\end{abstract}

${ }^{1}$ Escritor. Mestrando em Estudos Literários pelo Programa de Pós-Graduação em Letras da Universidade Federal do Piauí (UFPI). Autor do livro de contos No meio do tiroteio (Ed. Kazuá, 2017). E-mail: mouradeisaque@hotmail.com

Revista do GELNE, Natal/RN, Vol. 23 - Número 1: p. 83-98. Fevereiro. 2021 
its context of annihilation of subjectivities, this article seeks to reflect on the dynamics of identity deterioration in the inmate's world and the processes of personal disfigurement applied to the home confinement regime. In this perspective, the theoretical assumptions of canadian sociologist Erving Goffman (1987) are mobilized in discussions about total institutions and the main mechanisms of mortification associated with such establishments. The analyzes were carried out based on the original edition of the novel, published by the spanish publisher Siruela, in 2003. It is argued that the Boarding Home, as a supposed mental health home, seriously deviates from its therapeutic purpose, as the characters incorporate and reproduce the violence of the institutional sctructure that pleads whit them. In these circumstances, it is understood that the asylum space does not operate as a place of reception or care, but as a gear of opression, abandonment and extermination of human lives.

KEYWORDS: Boarding Home; Guillermo Rosales; Total institutions; Cuban literature.

\section{INTRODUÇÃO}

Escrito entre as sucessivas crises psicóticas e internações psiquiátricas do escritor cubano Guillermo Rosales (Havana, 1946 - Miami, 1993), o romance Boarding Home (2003) é considerado um registro implacável da experiência de confinamento de um dos nomes mais controversos da literatura hispano-americana. O livro, premiado no concurso Letras de Oro (1986), sofreu diversos embaraços editoriais à época de sua publicação original, razão pela qual durante muito tempo permaneceu inacessível ao grande público. Somente em 2004, cerca de onze anos após a morte do escritor, o romance passou a circular com mais frequência entre os leitores - em especial, a partir do lançamento da tradução francesa, editada pela Actes Sud. Atualmente, Rosales goza do reconhecimento da crítica e é considerado um autor fundamental no contexto da produção ficcional caribenha, sobretudo da chamada Geração Mariel (em referência ao grupo de intelectuais exilados durante o êxodo cubano da década de 80).

Professor, empregado de escritório e articulista, Rosales a princípio participou de forma ativa do projeto revolucionário castrista. Durante a juventude, uniu-se ao acampamento dos guerrilheiros na Sierra Maestra, centro de operações de combate contra a ditadura de Batista. Mais tarde, como jornalista, trabalhou em publicações de cadernos e periódicos que apoiavam a revolução, principalmente com artigos para a revista Mella, veículo de imprensa da Unión de Jóvenes Comunistas. Anos depois, decepcionado com a esquerda e com os rumos do país, tornou-se dissidente do regime. Em entrevista concedida à revista Mariel (1986, ano 1, vol. 3, tradução nossa), Rosales declarou que Boarding Home era "um romance escrito com ódio", "uma obra desoladora (...) onde não há misericórdia para ninguém nem mensagem de esperança", e que seus personagens "quase todos são cubanos afetados pelo totalitarismo castrista, lixos humanos que só sabem evocar sua dor" .

$\mathrm{Na}$ década de 80, o escritor partiu rumo aos Estados Unidos na intenção de reconstruir sua vida longe da ilha de Cuba, mas a realidade apresentada nem de longe o favoreceu: dias após sua chegada em Miami, teve problemas de adaptação e foi rejeitado pela família. Sem trabalho, sem dinheiro e padecendo de habituais crises nervosas, Rosales embarcou daí em diante em um acentuado processo de abandono pessoal: fumava obsessivamente, mal se alimentava e a certa altura havia perdido todos os dentes. Durante esse período, passou a transitar regularmente entre manicômios, hospícios e asilos, muitos deles fontes de inspiração para o seu único romance publicado em vida, Boarding Home (1987).

\footnotetext{
2 "una novela escrita con odio."

3 "una obra desoladora (...) donde no hay piedad para nadie y no hay mensaje de esperanza."

4 “(...) casi todos son cubanos afectados por el totalitarismo castrista, guiñapos humanos que sólo saben evocar su dolor."
}

Revista do GELNE, Natal/RN, Vol. 23 - Número 1: p. 83-98. Fevereiro. 2021 
Com efeito, o histórico clínico de Rosales indicava recorrentes problemas psiquiátricos. Além dos ataques de fúria e dos frequentes impulsos destrutivos, o escritor era atormentado por vozes e alucinações, tendo recebido em distintas circunstâncias o diagnóstico de esquizofrenia. Os constantes delírios e oscilações de humor constituíam a complexa personalidade de um indivíduo em permanente estado de conflito, vacilando entre a loucura e a lucidez. Do mesmo modo, as angústias do exílio, as dificuldades financeiras e o agravamento das enfermidades mentais do escritor afetaram progressivamente sua capacidade de seguir produzindo. Em seus últimos anos, Rosales havia alcançado o limiar da degradação física e mental. Em entrevista à Leyva Martínez (2007/2008, p. 47, tradução nossa), o escritor Carlos Victoria revelou que Guillermo estava obcecado com a ideia do suicídio: “(...) durante os últimos meses de sua vida, telefonava pontualmente às onze da manhã para anunciar que se mataria" 5 . Para Victoria, era como se o mal-estar tivesse se apoderado completamente do amigo: "[Rosales] estava alimentado pelo ódio, era seu motor principal. Um ódio contra a natureza humana. Não perdoava ninguém,

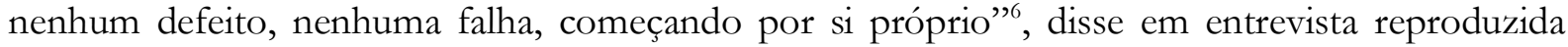
por López (2009, tradução nossa).

Tais condições contribuíram, em ampla medida, para a decisão do escritor de pôr fim à própria vida. Assim, numa manhã do mês de julho de 1993, aos 47 anos, Rosales cumpriu sua promessa: seu cadáver foi encontrado no apartamento onde havia passado a residir, na zona noroeste de Miami. Ao lado do corpo, o revólver que o escritor havia usado para disparar contra a própria cabeça - "(...) uma trinta e oito que ninguém sabe de onde ele tirou, porque não tinha nem o que comer" (ABREU, 1998, p. 138, tradução nossa) ${ }^{7}$. Além disso, uma carta dirigida ao amigo Carlos Victoria, por meio da qual Rosales exprimia seus últimos desejos: “(...) que meu cadáver seja cremado e minhas cinzas enterradas em qualquer cemitério. Não quero velórios nem cerimônias fúnebres" cadáver" (Velazco, 2015, apud ROSALES, 1993, tradução nossa). Em outro registro, o escritor sentenciou: "Não culpe ninguém por minha morte. Eu sou o único responsável"10 (Velazco, 2015, apud ROSALES, 1993, tradução nossa).

Rosales destruiu a maior parte de seus manuscritos, mas sua produção ficcional inclui pelo menos três volumes: os romances Boarding Home (1987) e El juego de la viola (1994, publicação póstuma) e o livro de contos El alambique mágico (escrito entre 1988 e 1990, parcialmente inédito). Para além do conhecimento de episódios particulares da vida do escritor, registra-se que a raiva, o pessimismo e a violência estão entre as principais marcas presentes em seu trabalho literário, motivo pelo qual a relação entre autor e obra se faz possível, inclusive na análise de Boarding Home. Isso porque Rosales transfere para o arcabouço da narrativa não apenas a contraversão que assinalava o regime político cubano à época de produção do romance, mas também a sua própria experiência de vida desafortunada. As tensões advindas do plano social, político e pessoal, por sua vez, ganham forma literária através dos processos de mortificação do sujeito e se concentram no espaço da home, alegoria do desmembramento identitário e da profanação do eu.

$\mathrm{Na}$ análise proposta neste estudo, em particular, observa-se a constituição ficcional do espaço manicomial no sentido de compreender as consequências que os instrumentos de dominação introjetados no mundo do internado assumem sobre a estrutura do eu. Nessa perspectiva, a pesquisa fundamenta-se nos pressupostos teóricos de Erving Goffman, extraídos

\footnotetext{
5 “(...) durante los últimos meses de su vida lo llamaba puntualmente a las once de la mañana para anunciarle que se quitaría la vida".

6 "[Rosales] estaba alimentado por el ódio, era su principal motor. Un odio contra la naturaleza humana. No perdonaba a nadie, ningún defecto, ninguna debilidad, empezando con él mismo".

7 “(...) una treinta y ocho que nadie sabe de dónde sacó porque no tenía ni con qué comer”.

8 “(...) que mi cadáver sea cremado y mis cenizas enterradas en cualquier cementerio. No quiero velorios ni ceremonias de enterramiento".

9 "No quiero familiares alrededor de mi cadáver".

10 "No se culpe a nadie de mi muerte. Yo soy el único responsable".
}

Revista do GELNE, Natal/RN, Vol. 23 - Número 1: p. 83-98. Fevereiro. 2021 
do livro Manicômios, Prisões e Conventos (1987), articulando-se ao desenvolvimento narrativo do romance de Guillermo Rosales.

\title{
1 Instituição total: epidemia da desumanização no mundo do internado
}

Há uma série de razões que tornam Boarding Home um livro único na história da ficção caribenha das últimas décadas. Isso porque o romance não é apenas o retrato de uma geração de dissidentes políticos exilados, insatisfeitos com a Revolução Cubana, mas também um mergulho profundo no desespero, na loucura e na crueldade humanas. José Abreu Felippe, em publicação intitulada Guillermo Rosales, la soledad e la cólera, assim caracteriza a obra:

\begin{abstract}
Boarding Home é uma visão de horror pelos olhos da vítima. Uma das representações do Marquês de Sade no asilo de Charenton projetada na parede mais miserável da Cidade Mágica. Um concerto de loucos e pobres desenraizados, condenados a um exílio interminável, dançando ao ritmo do Aqui o que importa é o dinheiro, enquanto exibem suas misérias e apodrecem, literalmente, na vida. William Figueras, o protagonista, se esforça em escapar através de Francis, que lhe entrega o seu corpo, enquanto ele lhe aperta o pescoço até quase estrangulá-la. Romeu e Julieta na versão do Apocalipse. Uma história cruel e sem piedade que não deixa espaços onde sentar-se e respirar (FELIPPE, 2005, p. 17 , tradução nossa) $)^{11}$.
\end{abstract}

Narrado em primeira pessoa, Boarding Home conta a história do personagem William Figueras, escritor cubano que após uma sucessão de crises psicóticas tenta estabelecer-se em Miami, nos Estados Unidos. Seu precário estado de saúde mental, agravado pela frustração de ver seus livros censurados em Cuba, impulsionam o protagonista a deixar a ilha. Seu objetivo é reconstruir uma nova vida, em busca de um lugar onde possa seguir produzindo literatura sem as imposições repressivas de um governo autoritário, como aquelas experenciadas sob o domínio do regime comunista. Mas, ao desembarcar no Aeroporto Internacional de Miami, o protagonista é confrontado com uma nova decepção. Os parentes que o esperavam no aeroporto contavam com a chegada de um jovem promissor, um vitorioso, com grande potencial para o american way of life. O cenário, contudo, revela-se completamente distinto: a família não encontra em William nenhum rastro de grandeza - depara-se apenas com um sujeito esfarrapado, cujo aspecto físico apresenta-se tão decadente quanto o descontrole psíquico. Em meio a esse súbito contraste, ao tomar consciência da situação, o próprio protagonista reage com estranhamento, destratando os familiares. Nesse momento, os frágeis laços que ainda pareciam vinculá-lo àquelas pessoas são definitivamente rompidos, e William acaba internado em um hospital psiquiátrico.

O personagem chega a compartilhar um curto período de convivência com uma de suas tias, Clotilde, que se compadece diante do estado do rapaz. Mas a agressividade de William e suas reações emocionais explosivas impedem a continuidade da relação. A tia decide então colocá-lo na boarding home, uma espécie de asilo psiquiátrico destinado a idosos, desabrigados e incapacitados mentais. $\mathrm{Na}$ boarding home, portanto, estão todos aqueles que potencialmente ameaçam ou perturbam a ordem pública: os inadaptados, indesejados, maníacos, doentes, alcoólatras e velhos. Indivíduos que não devem fazer parte da convivência cotidiana porque em alguma medida se desviam da hegemonia da norma. Largados à própria sorte, resta-lhes tãosomente a submissão a um rigoroso ciclo de deterioração pessoal, cujos resultados mais evidentes culminam no desamparo e na violação sistemática da estrutura identitária. O que o hospício lhes

11 "Boarding Home es una mirada al horror desde los ojos de la víctima. Una de las representaciones del Marqués de Sade en el asilo de Charenton proyectada sobre la pared más desvalida de la Ciudad Mágica. Un concierto de locos y pobres desarraigados, condenados por un exilio interminable, a bailar al ritmo de Aquí lo que importa es el cash, mientras exhiben sus miserias y se pudren, literalmente, en vida. William Figueras, el protagonista, se empeña en escapar a través de Francis, que le entrega su cuerpo, mientras él le aprieta el cuello hasta casi estrangularla. Romeo y Julieta en versión de Apocalipsis. Una historia cruel y despiadada que no deja espacios donde sentarse a respirar."

Revista do GELNE, Natal/RN, Vol. 23 - Número 1: p. 83-98. Fevereiro. 2021 
reserva, além da humilhação e do confinamento, é simplesmente a violência, o sofrimento e a miséria.

O relato do protagonista confunde-se, em muitos aspectos, com o testemunho do próprio escritor Guillermo Rosales, razão pela qual denotam-se diversos elementos de ficção autobiográfica presentes no romance. Dentre as semelhanças mais significativas, destacam-se a experiência do exílio, o fato de tanto o autor quanto o personagem serem escritores e padecerem de transtornos mentais graves, além de ambos terem passado boa parte da vida internados em instituições psiquiátricas. Segundo Martínez (2002, p. 105, tradução nossa), Boarding Home referese a Happy Home, um dos asilos pelos quais Rosales passou: "[Rosales] escreveu Boarding Home em mais ou menos dois anos. O romance reflete sobretudo o panorama de Happy Home, um dos tantos asilos onde viveu" $"$.

William Figueras reconhece a si próprio como um decadente, um fracassado; compreende que não há espaço para ele entre os "vencedores". Seu lugar é na boarding home, zona destinada à "escória da vida". Tal constatação fica evidente pela própria atitude compassiva do personagem, ao não demonstrar qualquer resistência quanto à decisão da tia em interná-lo. Esta, por outro lado, tenta se convencer de que não há alternativa possível para William, forçando-o a acreditar que nada mais se pode fazer.

A partir daí, o cotidiano do protagonista é atravessado por seres destroçados, consumidos pela loucura e pelo desengano. William descreve a realidade dessas criaturas fragmentadas, cuja condição de desajuste revela-se tão profunda quanto irreversível. Para esses personagens não há possibilidade de reparação - eles assumem integralmente a metáfora do esgotamento físico e psíquico na boarding home. Representam também um dos principais centros de conflito do romance, através dos quais se espelham a sujeira, a miséria, o terror e a brutalidade. Escobar (2009, p. 64, tradução nossa), ao analisar as estruturas fundamentais da obra, afirma que "O romance (...) se constrói a partir dos limites entre a loucura e a sanidade, sono e vigília, espaços exteriores e interiores, Miami e Cuba (...). Com raiva, com cólera, mas com resignação, o protagonista se constitui um exilado total" ${ }^{\prime 13}$.

No sanatório, William apaixona-se por Francis, outra cubana também exilada. Esse sentimento o faz resgatar aos poucos a esperança de um novo futuro. Na tentativa de viverem juntos longe do asilo, os dois decidem fugir, mas acabam sendo apanhados pela polícia. William, após uma curta permanência em outro hospital psiquiátrico, é devolvido à home, ao passo que Francis é retirada do manicômio pela família. O final do enredo expõe a ideia de que não há chance de mudança para William: o hospício é o seu lugar definitivo.

Boarding home! Boarding home! Já faz três anos que vivo nesta boarding home. Castaño, o velho centenário que quer morrer constantemente, continua gritando e fedendo a mijo. Ida, a grande dama em ruínas, continua sonhando que seus filhos de Massachusetts virão um dia resgatá-la. Eddy, o louco versado em política internacional, continua atento aos noticiários da televisão e pedindo aos gritos uma terceira guerra mundial. Reyes, o velho caolho, continua supurando humor por seu olho de vidro. Arsenio continua mandando. Curbelo segue vivendo sua vida de burguês com o dinheiro que tira de nós (ROSALES, 2003, p. 99, tradução nossa) ${ }^{14}$.

\footnotetext{
12 "Escribió Boarding Home en unos dos años. La novela refleja sobre todo el panorama de Happy Home, uno de los tantos asilos donde vivió."

13 "La novela (...) se construye desde los bordes entre la locura y la cordura, el sueño y la vigilia, los espacios exteriores e interiores, Miami y Cuba (...). Con rabia, con cólera pero con resignación, el protagonista se termina de constituir en exiliado total."

14 "¡Boarding home! ¡Boarding home! Ya hace tres años que vivo en este boarding home. Castaño, el viejo centenario que quiere morir constantemente, sigue gritando y apestando a orín. Ida, la gran dama venida a menos, continúa soñando que sus hijos de Massachusetts vendrán un día a rescatarla. Eddy, el loco versado en política internacional, sigue pendiente de los noticieros de televisión, y pidiendo a gritos una tercera guerra mundial. Reyes, el viejo tuerto,
} 
A conclusão, ao reafirmar a continuidade dos destinos degradantes de cada um dos internos, faz com que o espaço da boarding bome assuma um papel decisivo para o desenvolvimento e estruturação da narrativa. As ações dos personagens e os seus respectivos desdobramentos circunscrevem-se em função do asilo e desenvolvem-se segundo as possibilidades que o próprio manicômio impõe. Nesse sentido, a relação de William com o espaço habitado é fundamentalmente simbiótica: por mais que tente encontrar outro caminho, o personagem carrega consigo o inescapável estigma da "casa dos escombros humanos".

Assim, considerando a relevância do espaço para a compreensão das ações dos personagens no romance, dialogamos com o estudo do sociólogo canadense Erving Goffman (1987), ao analisar as relações travadas em instituições totalizantes. Em seu estudo, o sociólogo aponta uma série de características desses estabelecimentos que os tornam ambientes propícios à aniquilação de subjetividades. Contudo, antes de analisarmos este ponto específico, pretendem-se destacar algumas particularidades no cenário da home que fornecem diferentes perspectivas às caracterizações elencadas por Goffman em Manicômios, Prisões e Conventos.

Goffman (1987, p. 11) conceitua uma instituição total como um lugar destinado à residência ou trabalho "onde um grande número de indivíduos com situação semelhante, separados da sociedade mais ampla por considerável período de tempo, levam uma vida fechada e formalmente administrada". Consequentemente, em uma instituição dessa natureza, todos os aspectos que compõem a vida são realizados no mesmo local e sob comando de uma única autoridade. As atividades diárias dos participantes acontecem de forma conjunta, nos mesmos horários, sendo compartilhadas por um grupo relativamente grande de pessoas, todas elas tratadas de maneira uniforme. Além disso, um sistema de regras formais define toda a sequência de atividades a serem executadas pelos internos, impostas e supervisionadas por uma equipe dirigente. Essa instrumentalização coletiva compõe um plano racional único, "supostamente planejado para atender aos objetivos oficiais da instituição" (GOFFMAN, 1987, p. 17-18).

De acordo com o sociólogo (1987, p. 16), todas as instituições, pela sua própria natureza, têm tendências de "fechamento", isto é, reforçam naturalmente a construção de barreiras simbólicas com o mundo externo. Mas essas barreiras ficam particularmente evidenciadas quando analisamos as instituições de caráter total, dada a estruturação dos esquemas físicos aliados à sua constituição, tais como a existência de portas fechadas, paredes altas, arames farpados, fossos, florestas etc. Os esquemas físicos, nesse contexto, reproduzem a essência da finalidade institucional e reiteram o insulamento das organizações em torno de si mesmas. Em vista disso, pela lógica operacional de privação da liberdade dos internos e do rigoroso controle afeto a essas instituições, verifica-se que tais esquemas exercem papel fundamental enquanto medidas de contenção, frente às possibilidades de fuga ou evasão - daí a necessidade de se adotar diferentes estratégias de monitoramento ambiental.

De forma exemplificativa, o sociólogo (1987, p. 16-17) classifica as instituições totais em cinco grupos básicos, sendo eles: a) instituições criadas para cuidar de pessoas consideradas "incapazes" e "inofensivas", por exemplo, as casas para cegos, velhos, órfãos e indigentes; b) instituições criadas para cuidar de pessoas consideradas "incapazes de cuidar de si mesmas" e que representam, ainda que não-intencionalmente, uma ameaça à comunidade; por exemplo, sanatórios para tuberculosos e leprosários e hospitais psiquiátricos; c) instituições criadas para proteger a comunidade de perigos intencionais; por exemplo, as cadeias, as penitenciárias, campos de concentração e campos de prisioneiros de guerra; d) instituições criadas para realizar tarefas de trabalho específicas, tais como quartéis, navios, escolas internas, campos de trabalho, colônias, mansões etc. e) instituições criadas para servirem como refúgio do mundo ou locais de instrução para religiosos; por exemplo, abadias, mosteiros, conventos e demais claustros.

continúa supurando humor por su ojo de vidrio. Arsenio sigue mandando. Curbelo prosigue viviendo su vida de burgués con el dinero que nos saca". 
Tomando por base os conceitos e a classificação supracitados, pode-se verificar que a estrutura da boarding home, na perspectiva do romance de Rosales, não se situa especificamente em nenhuma das categorias, embora compreenda similaridades entre as alíneas "a" e "b". Isso porque o espaço asilar delineado na narrativa compõe-se de uma esfera híbrida, anômala, com peculiaridades que amplificam as estruturas apresentadas pela literatura sociológica goffmaniana.

Tradicionalmente, o isolamento dos loucos em manicômios e prisões justifica-se pela segregação de um grupo socialmente indesejável, cuja presença representa ameaças potenciais à manutenção da ordem e ao bem-estar das outras pessoas. Esses padrões de tratamento, por sua vez, estão historicamente vinculados à construção simbólica de que "o louco, para sarar, devia ser removido da ordem social (...) e colocado em um meio ambiente isolado e especialmente criado onde prevalecessem a ordem e as rotinas disciplinadas" (TUAN, 2005, p. 317). Daí a configuração repressiva do hospital psiquiátrico: “(...) seu aspecto exterior maciço, tão diferente das casas comuns, simbolizava o poder de um sistema totalitário. Porém, o poder tinha como finalidade restabelecer a ordem mental perturbada" (TUAN, 2005, p. 317-318).

Registra-se que a boarding home, no romance de Rosales, não se destina exclusivamente à recepção de loucos, mas também de idosos, imigrantes, doentes, indigentes e quaisquer outros que já não encontram onde refugiar-se: “(...) um desses abrigos marginais para onde vai a gente abandonada pela vida. Loucos em sua maioria. Mas, às vezes, há também velhos deixados por suas famílias para que morram de solidão e não atrapalhem a vida dos vencedores"15 (ROSALES, 2003, p. 11, tradução nossa). Por mais que grande parte dos internos padeça de doenças mentais, o lugar não pode ser tomado unicamente como um manicômio ou hospício, no sentido comum do termo. A permanência de deficientes físicos, velhos, exilados e ex-detentos baliza a definição mais genérica, encetando novos desdobramentos no rol das instituições apresentadas por Goffman. Além disso, não se verifica a presença de médicos, enfermeiros ou profissionais de saúde atendendo aos internos. Os medicamentos são ministrados pelos próprios funcionários, ou pelo dono do estabelecimento, sem maiores preocupações com o estado de saúde geral dos loucos ou com a evolução de seus respectivos quadros clínicos. Dessa forma, embora o narrador se refira com frequência ao asilo como um hospício - e até sejam observados numerosos detalhes que poderiam caracterizá-lo nesse sentido -, é importante não reduzi-lo unicamente como tal, sob o risco de simplificar certos aspectos sensíveis à análise da estrutura espacial.

Assim, ao contrário da configuração tradicional dos manicômios, no romance os internos não renunciam completamente o contato com o mundo externo. O companheiro de quarto de William, por exemplo, trabalha meio-expediente em uma pizzaria. O próprio William, em diversas cenas, tem um relativo grau de liberdade de entrada e saída da home: caminha sem rumo pelas ruas de Miami, observando o movimento dos carros e das pessoas. Passeia, recebe visitas pontuais de um amigo (El Negro) e percorre o centro da cidade. Ademais, não se observa na narrativa a caracterização de "esquemas físicos" destacados por Goffman (portões fechados, grades, paredes altas, cercas ou outros mecanismos de repressão), o que realça a ideia de que os processos de mortificação excedem a estrutura física e a própria direção mantida pela instituição.

A configuração do espaço, desse modo, é produzida em condições limítrofes, fronteiriças. Escobar (2009, p. 51) a classifica em termos de "bordas", "arestas" ou "margens": zonas extremas através das quais o protagonista circula, sem encontrar em nenhuma delas a possibilidade de libertação. Essas arestas estão representadas não apenas em termos de disposição espacial, mas também no uso da língua, na caracterização dos personagens, nos conflitos ideológicos e na dualidade entre a sanidade e a loucura de William.

O espaço da boarding home, nesse contexto, reafirma o processo de desumanização e violação que os loucos sofrem, desintegrando-os enquanto sujeitos. É importante observar que a

15 “(...) uno de esos refugios marginales a donde va la gente desahuciada por la vida. Locos en su mayoría. Aunque, a veces, hay también viejos dejados por sus famílias para que mueran de soledad y no jodan la vida de los triunfadores".

Revista do GELNE, Natal/RN, Vol. 23 - Número 1: p. 83-98. Fevereiro. 2021 
home se consolida como um negócio lucrativo para o proprietário, o sr. Curbelo, que se aproveita dos benefícios pagos pelo Estado e, a um só tempo, obriga os internos a conviverem em condições humilhantes, sem nenhum conforto. $\mathrm{O}$ contato reiterado com situações de indignidade - lençóis e travesseiros sujos; inexistência de produtos básicos de higiene; banheiros em péssimos estados, entre outras circunstâncias de privação e desumanização, apenas reforçam a criação de um ambiente hostil, incapaz de promover aos internos qualquer possibilidade de recuperação da sanidade (ou, ao menos, de redução dos danos psicológicos).

As dinâmicas de desfiguração pessoal e "mutilação do eu" no mundo do internado, por conseguinte, são precedidas por uma sucessão de práticas que Goffman denomina "processos mortificantes". A tese central do sociólogo é a de que, ao ingressarem nesses ambientes, os indivíduos passam por um intenso processo de deterioração identitária, ou seja, os conceitos que tinham de si mesmos e os papéis sociais que exerciam anteriormente em seus mundos domésticos tornam-se progressivamente destituídos de valor. Os sentidos de trabalho, família e relações interpessoais sofrem profundos desajustes, sendo o interno completamente dominado pelo mundo institucional.

\begin{abstract}
O novato chega ao estabelecimento com uma concepção de si mesmo que se tornou possível por algumas disposições sociais estáveis no seu mundo doméstico. Ao entrar, é imediatamente despido do apoio dado por tais disposições. $\mathrm{Na}$ linguagem exata de algumas de nossas mais antigas instituições totais, começa uma série de rebaixamentos, degradações, humilhações e profanações do eu. O seu eu é sistematicamente, embora muitas vezes não intencionalmente, mortificado. Começa a passar por algumas mudanças radicais em sua carreira moral, uma carreira composta pelas progressivas mudanças que ocorrem nas crenças que têm a seu respeito e a respeito dos outros que são significativos para ele (GOFFMAN, 1987, p. 24).
\end{abstract}

Para Goffman, tais rompimentos configuram formas iniciais de mutilação do eu (barreiras do internado com o meio externo; privação da vida familial, despojamento dos papéis sociais desempenhados pelo indivíduo etc.). $\mathrm{O}$ autor $(1987$, p. 25) destaca que alguns desses papéis são restauráveis, quando da reintegração do internado ao mundo externo; outros, no entanto, são irrecuperáveis (por exemplo, o prejuízo do tempo em relação ao progresso profissional ou educacional do indivíduo, bem como na educação de seus filhos). Essa perda permanente também está associada ao conceito de "morte civil", segundo o qual os internados são temporariamente privados dos seus direitos civis, podendo inclusive ter alguns desses direitos permanentemente suprimidos.

O sociólogo compreende ainda que, no contexto das instituições totais, a ação mortificante é regulada por uma série de processos ou mecanismos que atuam na mutilação da estrutura do eU, entre eles, as indignidades físicas; as exposições contaminadoras; as privações ou ingestões forçadas, e assim por diante. Grande parte dessas dinâmicas, em maior ou menor medida, estão presentes no romance Boarding Home e serão detalhados a seguir.

\title{
2 Deterioração identitária e mortificação do eu em Boarding Home
}

Goffman $(1987$, p. 20) aponta que nas instituições totais existe uma divisão entre o grupo de internados (grupo controlado) e a equipe dirigente (responsáveis diretos pelo controle). Enquanto os internos possuem restrições de informações e de acesso ao mundo exterior, a equipe de supervisão geralmente trabalha em um esquema de oito horas diárias, com livre acesso ao mundo exterior. Os agrupamentos também são marcados por uma grande distância social, com supervisão continuada e comunicação limitada entre si. Os dois grupos, em razão de suas diferenças, tendem a agir com desconfiança e hostilidade recíprocas. Por esse motivo, o sociólogo (1987, p. 20) afirma que entre ambos "desenvolvem-se mundos sociais e culturais diferentes, que caminham juntos com pontos de contato oficial, mas com pouca interpenetração". 
A boarding bome, no romance de Rosales, a princípio funciona de maneira semelhante: William e os outros personagens são apartados do convívio social ("mundo externo") e passam a ser vigiados por uma "equipe dirigente", formada pelo sr. Curbelo, proprietário do estabelecimento, e Arsenio, o encarregado. Há ainda uma terceira personagem, Caridad, funcionária responsável pela distribuição da comida entre os loucos na home. O enredo, por conseguinte, é marcado por diversos momentos de tensão e conflitos entre os personagens, a exemplo da relação mantida entre internos e dirigentes. Xingamentos, agressões, ameaças e castigos físicos são episódios recorrentes, inclusive entre os próprios pacientes.

Goffman considera que quaisquer meios de desmoralização através de humilhações, insultos ou gozações constituem "indignidades físicas", circunstâncias em que os indivíduos são obrigados a assumir posturas degradantes. Esses padrões de mortificação podem ser observados com frequência nas descrições de William. O sr. Curbelo, além de desviar a maior parte dos recursos da casa, ameaça constantemente expulsar os hóspedes: “(...) 'Não gosta? Se não gosta, vá embora!' Mas... quem vai? A rua é dura. Até para os loucos que têm a cabeça na lua"16 (ROSALES, 2003, p. 16, tradução nossa). Arsenio, o encarregado, dedica os dias a tomar cerveja, abusar sexualmente das mulheres do asilo e roubar os objetos pessoais dos internos. Seu trabalho consiste em controlar os insanos, sobretudo mediante o uso da violência. Na prática, é quem assume a chefia do lugar - e reproduz, em grande medida, a encarnação da corrupção e da brutalidade na bome: “(...) dá chutes em Reyes, o caolho; abre as gavetas de qualquer pessoa em busca de dinheiro, e anda por toda a boarding home com uma faca afiada na cintura"17 (ROSALES, 2003 , p. 23, tradução nossa). Arsenio também incita agressões entre os pacientes, destilando deliberadamente seu sadismo contra os internos, principalmente entre os mais instáveis: "Às vezes, [Arsenio] pega essa faca, entrega a René, o retardado, e diz apontando para Reyes, o caolho: 'Enfie nele!'. (...) 'Enfie no pescoço, que é a parte mais macia'. (...) 'É assim que se dá facada!', explica a René. 'Assim, assim, assim!"18 (ROSALES, 2003, p. 23, tradução nossa).

O romance conta com diversas passagens em que se expõem os castigos físicos aplicados por Arsenio contra os loucos. Esse excesso de sanções oriundos da equipe dirigente reflete-se pelo uso abusivo - e, muitas vezes, gratuito - da violência física, quaisquer que sejam as razões envolvidas. Pode-se ser agredido por sujar os cômodos, fazer barulho ou promover badernas, assim como pode-se ser agredido sem motivo nenhum. Não há correspondência direta entre as ações dos internos e as sanções infligidas, o que de certa maneira torna as punições desarrazoadas e imprevisíveis.

Goffman inclui ainda, entre os meios de mortificação do eu, as chamadas exposições contaminadoras, através das quais "a fronteira que o indivíduo estabelece entre seu ser e o ambiente é invadida e as encarnações do eu são profanadas" (GOFFMAN, 1987, p. 31). Ou seja, se no mundo externo o indivíduo pode manter os objetos que se relacionam aos seus próprios sentimentos fora do alcance de coisas estranhas ou contaminadoras, no mundo interno ele é obrigado a partilhar sua imagem, seu espaço e desfazer-se de seus bens. Tais condições podem incluir, por exemplo, a divisão de dormitórios e a existência de banheiros expostos, de modo que "os presos e os doentes mentais não podem impedir que os visitantes os vejam em circunstâncias humilhantes" (GOFFMAN, 1987, p. 32). No romance, a boarding home é uma espécie de casa adaptada, cuja estrutura original foi dividida em doze pequenos quartos, compartilhados entre vinte e três pacientes (cada quarto com duas camas). William habita o quarto número 4, no

\footnotetext{
16 ‘(...) ¿No te gusta? Pues si no te gusta ¡vete! Pero... ¿quién se va a ir? La calle es dura. Aun para los locos que tienen los sesos en la luna".

17 "entonces le da patadas en Reyes, el tuerto; abre las gavetas de cualquiera en busca de dinero, y se pasea por todo el boarding home con un cuchillo afilado a la cintura".

18 A veces, [Arsenio] toma este cuchillo, se lo da a René, el retardado, y le dice señalando a Reyes, el tuerto: 'Méteselo!'. (...) 'Méteselo por el cuello, que es la parte más blandita'. (...) ‘Así se dan las puñaladas!'; le explica a René. ‘Así, así, así!’.
} 
mesmo lugar "onde dorme outro louco cujo ronco lembra o barulho de uma serra elétrica" 19 . Além disso, a casa possui apenas três banheiros, sendo um deles reservado ao sr. Curbelo, para que não precise ter contato com a sujeira dos loucos.

Nesse aspecto, Goffman destaca que, nesses estabelecimentos, as instalações físicas costumam representar os tipos mais evidentes de exposição contaminadora (locais sujos, quartos em desordem, privadas sem assentos). Do mesmo modo, os objetos ofertados aos internados também costumam ser fontes usuais de contaminação: alimentos estragados ou sujos, toalhas sem higienização, roupas impregnadas com suores de outros internos etc. Nas descrições da home denotam-se recorrentes indicações desse processo mortificante. Os poucos banheiros disponíveis na casa apresentam problemas; além disso, nem sequer itens básicos de higiene são ofertados aos internos: "Há três banheiros, mas um deles (o melhor) é do chefe, o sr. Curbelo. Os outros dois estão sempre com as privadas entupidas, pois alguns dos hóspedes jogam camisas velhas, lençóis, cortinas e outros panos que usam para limpar o traseiro. O sr. Curbelo não dá papel higiênico"20 (ROSALES, 2003, p. 15, tradução nossa). A alimentação dos pacientes é servida em péssimas condições, quase sempre em quantidades insuficientes. $O$ sr. Curbelo, a título de vantagem pessoal, subtrai boa parte dos recursos destinados à manutenção da casa, recusando-se a investir o dinheiro que recebe dos familiares dos hóspedes e dos subsídios encaminhados pelo governo americano à assistência da boarding home. Dessa forma, para evitar essas despesas e manter o assoberbado padrão de vida de sua família, o sr. Curbelo é quem prepara a comida:

\begin{abstract}
De modo que o próprio Curbelo, com a sua cara deslavada de burguês, é quem faz a sopa todos os dias. Ele a cozinha da maneira mais simples: colhendo com a mão um punhado de ervilhas ou lentilhas e jogando-as (plaf!) em uma panela de pressão. Talvez acrescente um pouco de alho em pó. O restante, o arroz e o prato principal, vem de um restaurante em domicílio chamado Sazón, cujos donos, como sabem que se trata de uma casa de loucos, escolhem o pior do cardápio e mandam de qualquer maneira em duas grandes panelas gordurosas. Deviam mandar comida para vinte e três, mas só mandam comida para onze. O sr. Curbelo considera que é o suficiente (ROSALES, 2003, p. 15-16, tradução nossa) ${ }^{21}$.
\end{abstract}

O refeitório, administrado pela mulata Caridad, também serve à manutenção dos constrangimentos praticados pelos demais funcionários, atingindo os internos mediante a imposição de indignidades físicas e privações alimentares. A própria escolha pelo nome da personagem, Caridad, reflete um certo grau de ironia do autor, ao considerar-se o nível de egoísmo e desumanidade nas ações da personagem (o oposto do que se espera de alguém cujo nome evoca uma das mais nobres virtudes da cristandade e do amor ao próximo). Em Cuba, Caridad havia sido presa por esfaquear o marido. Mais tarde, nos Estados Unidos, encontra um emprego na boarding home, prestando suporte às avarezas do sr. Curbelo e ignorando as perversões de Arsenio. O processo de desumanização dos pacientes ocorre inclusive ao observar Caridad alimentando seus cachorros, em casa, com a comida que deveria ser ofertada aos loucos.

A privação alimentar, somada à impossibilidade de reações significativas para mudar o contexto, torna a narração de William Figueras uma fala consciente sobre a destruição da

\footnotetext{
19 "donde duerme otro loco cuyo ronquido recuerda el ruido de una sierra eléctrica".

20 "Hay tres baños, pero uno de ellos (el mejor) es del jefe, el señor Curbelo. Los otros dos tienen siempre los inodoros tupidos, pues algunos de los huéspedes meten en ellos camisas viejas, sábanas, cortinas y otros artículos de tela que usan para limpiarse el trasero. El señor Curbelo no da papel higiénico".

21 "De modo que el mismo Curbelo, con su carota de burgués, es el que hace el potaje todos los días. Lo cocina de la manera más sencilla; cogiendo con la mano un puñado de chícharos o lentejas y metiéndolos (iplaf!) en una olla a presión. Quizás le echa un poco de ajo en polvo. Lo otro, el arroz y el plato fuerte, viene de una cantina a domicilio llamada Sazón, cuyos dueños, como saben que se trata de una casa de locos, escogen lo peor del repertorio y lo mandan de cualquier manera en dos grandes cazuelas grasientas. Debían enviar comida para veintitrés, pero solo mandan comida para once. El señor Curbelo considera que es bastante".
} 
individualidade e da própria humanidade dos internos, condenados ao estigma da loucura e à falta de opções fora daquele espaço. O sr. Curbelo também reconhece o medo que os loucos nutrem em relação à rua, de modo que suas ameaças surtem o efeito desejado: preservam a ordem e protegem a administração de possíveis insurreições ou protestos dos hóspedes.

Outro aspecto relevante nessa dinâmica diz respeito aos momentos em que o protagonista relata seu desconforto durante as refeições. Como se não bastassem seus problemas de apetite, William se vê obrigado a alimentar-se daquela comida repugnante, ao lado de companheiros igualmente repulsivos, na "mesa dos intocáveis": Reyes, o velho que come com as mãos e cujo olho de vidro supura um líquido amarelo; Hilda, a velha decrépita que fede a urina e cuja metade da comida cai na roupa enquanto come; e Pepe, o retardado, que mastiga ruidosamente e que deixa escapar arroz e ervilhas ao redor da cara. Ao contrário dos loucos, Arsenio e os demais funcionários não se alimentam da mesma comida, muito menos compartilham os mesmos cômodos. Goffman reconhece nessas relações sociais forçadas com "companheiros indesejáveis" uma derivação do mecanismo de contaminação, na medida em que "quando a agência de contaminação é outro ser humano, o internado é ainda contaminado por contato interpessoal imposto e, consequentemente, uma relação social imposta" (GOFFMAN, 1987, p. 34).

Ainda quanto às exposições contaminadoras das instalações físicas, a narração de William revela com mais detalhes a ambientação opressiva mantida na home. Os quartos dos internos não dispõem de nenhum conforto, tampouco privacidade ou asseio, com penosas condições de ocupação. No romance, há diversos fragmentos que expõem essas circunstâncias: “(...) Vou ao banheiro urinar. A privada está entupida com um lençol que jogaram lá dentro. Mijo sobre o lençol. Depois lavo o rosto com um pedaço de sabonete que encontro na pia" 22 (ROSALES, 2003 , p. 26, tradução nossa). Ou ainda: "Volto ao meu quarto e me deixo cair na cama pesadamente. $\mathrm{O}$ travesseiro fede a suor antigo. Suor de outros loucos que passaram por aqui e se desidrataram entre estas quatro paredes"23 (ROSALES, 2003, p. 19, tradução nossa). E, também, quando o sr. Curbelo apresenta o quarto onde William será hospedado: "Esta é sua cama [Curbelo] diz, sem olhar para mim. - Esta é sua toalha - e aponta para uma toalha puída e cheia de manchas amarelas"24 (ROSALES, 2003, p. 17, tradução nossa). Por fim, "(...) pego minha toalha sebosa e um pedaço de sabonete e vou ao banheiro. O banheiro está inundado. Alguém meteu na privada uma jaqueta de couro. O chão está cheio de fezes, papéis e outras imundícies" 25 (ROSALES, 2003, p. 58, tradução nossa).

As indignidades físicas e exposições contaminadoras também se revelam nos assédios sexuais e estupros cometidos no manicômio, tanto pela equipe de funcionários, como também entre os próprios loucos. Arsenio protagoniza muitas dessas cenas, ao usar a personagem Hilda para satisfazer-se sexualmente. Arsenio dispõe do corpo de Hilda e a obriga a manter relações sexuais com ele, impondo-lhe seus arbítrios: "- Hilda! - [Arsenio] chama depois. E lá vem Hilda, a velha decrépita que fede a urina. Arsenio toca o sexo da velha por cima da roupa e diz: - Lave isto hoje! - Sai, homem! - protesta Hilda, indignada. E Arsenio cai na risada"26 (ROSALES, 2003, p. 23, tradução nossa). Esses ataques, além do rebaixamento moral e dos constrangimentos

\footnotetext{
22 "Voy al baño a orinar. El inodoro está tupido por una sábana que han metido dentro. Orino sobre la sábana. Luego me lavo la cara con una pastilla de jabón que encuentro sobre el lavabo".

23 “(...) Regreso a mi cuarto y me dejo caer sobre la cama con pesadez. La almohada apesta a sudor viejo. Sudor de otros locos que han pasado por aquí y se han deshidratado entre estas cuatro paredes".

24 “- Ésta es tu cama - dice, sin mirarme. Ésta es tu toalla - y señala una toalla raída y llena de manchas amarillas".

25 “(...) busco mi toalla mugrosa y una astilla de jabón y me encamino al baño. El baño está inundado. Alguien ha metido en la taza un jacket de cuero. El suelo está lleno de heces, papeles y otras inmundicias”.

26 “- ¡Hilda! - llama después. Y viene Hilda, la vieja decrépita que apesta a orín. Arsenio le toca el sexo por encima de la ropa y le dice: - ¡Lávatelo hoy!

- ¡Fuera, hombre! - protesta Hilda, indignada. Y Arsenio se echa a reír.
} 
íntimos, conforme aponta Goffman, retiram do indivíduo a capacidade de assumir o controle sobre o próprio corpo e as próprias vontades, invadindo o território do eu.

Como dito anteriormente, os assédios na boarding home não se limitam à figura da equipe dirigente. Nas relações entre os hóspedes também são recorrentes as manifestações de violação do corpo. Napoleão, o anão, denuncia as investidas de Tato, seu companheiro de alojamento ${ }^{27}$. William, por seu turno, com frequência assedia Francis. Ao vê-la pela primeira vez, aliás, ciente das perturbações mentais da jovem, ele passa a acariciá-la. Francis, impotente, reage passivamente aos abusos do protagonista:

Há uma louca sentada em frente ao aparelho [de TV]. (...) Me sento ao seu lado. Olho em volta. Não há ninguém. Estão todos no café da manhã. Estendo a mão até o joelho da louca:

- Sim, meu céu - ela diz, sem olhar para mim.

Subo a mão e chego às coxas. Ela deixa que eu o faça sem protestar. (...) Subo a mão mais um pouco e alcanço o sexo da louca. Aperto.

- Sim, meu céu - ela diz, sem parar de encarar a televisão. (...)

Começo a acariciar seu sexo com as unhas.

- Sim, meu céu - ela diz. - Tudo o que você quiser, meu céu.

Me dou conta de que ela está tremendo de medo. Desisto de tocá-la. Ela me dá pena. Pego sua mão e dou um beijo.

- Obrigado, meu céu - diz com uma vozinha apagada (ROSALES, 2003, p. 47-48, tradução nossa) ${ }^{28}$.

No trecho em destaque, observa-se que a personagem não demonstra ter controle de suas reações emocionais, manifestando sua vontade de maneira ambígua e confusa. A expressão da moça não condiz com o comportamento usual do desejo. Embora ela consinta verbalmente os toques de William, sua postura receosa e ao mesmo tempo apática reafirma o grau de instabilidade da jovem. Isso fica particularmente evidenciado no desenvolvimento da cena, quando Arsenio vai ao encontro de William e de Francis. Depois de perguntar ao protagonista o que ele acha da "nova aquisição" do manicômio, referindo-se ao recém-ingresso da hóspede na boarding home, Arsenio introduz o pé entre as coxas de Francis, tentando penetrar-lhe o sexo. A reação dela, no entanto, é semelhante: “- Sim, meu céu - diz Francis, sem deixar de olhar a televisão. - O que vocês quiserem, meus céus. Treme. Treme tanto que parece que os ossos dos ombros vão se descolar" ${ }^{29}$ (ROSALES, 2003, p. 48-49, tradução nossa).

\footnotetext{
27 “- Señor, señor... - me dice [Napoleón]. - ¡Ése! - y señala a un loco llamado Tato, cuya cara parece la de un viejo boxeador. - ¡Ése me la tocó!

- No hables mierdas - dice Tato.

- Me la tocó - sostiene Napoleón. Ayer, en mi cuarto, entró por la noche iy me la tocó!

(...) Ida, la gran dama venida a menos, me mira con indignación:

- ¡Lo que hay que ver! - dice. - ¡Lo que hay que oír!”

28 "Hay una loca sentada frente al aparato [de TV]. (...) Me siento a su lado. Miro alrededor. No hay nadie. Todos están en el desayuno. Extiendo la mano hacia la loca y se la pongo en una rodilla.

- Sí, mi cielo - dice ella, sin mirarme.

Subo la mano y llego hasta sus muslos. Ella se deja hacer sin protestar. (...) Subo la mano un poco más y llego al sexo de la loca. Se lo aprieto.

- Sí mi cielo - dice ella sin dejar de mirar el televisor. (...)

Comienzo a acariciarle el sexo con las uñas.

- Sí, mi cielo - dice. - Lo que tú quieras, mi cielo.

Me doy cuenta de que está temblando de miedo. Desisto de tocarla. Me da lástima. Le cojo una mano y se la beso. - Gracias, mi cielo - dice con una vocecita apagada".

29 “- Sí, mi cielo - dice Francis, sin dejar de mirar al televisor. - Lo que ustedes quieran, mis cielos. Tiembla. Tiembla tanto que parece que los huesos de los hombros se le van a zafar".
} 
A descrição do narrador sugere o medo e o desconforto da personagem diante dos dois homens (o tom de vOz, a impossibilidade de encarar os agressores, a postura corporal, a dificuldade de responder emocionalmente às ações). Ainda assim, a personagem é incapaz de externalizar o pavor que a acomete. Ao longo do romance esses episódios se repetem: William coage Francis em diversos momentos, estuprando-a e sufocando-a para dar vazão à raiva que o espaço do hospício e as situações de violação também impunham para ele. Dessa forma, o protagonista absorve os hábitos de coação sofridos e projeta seu ódio contra a personagem feminina, duplamente marginalizada.

Ao analisar o contexto espacial construído no romance, Escobar (2009) relaciona algumas das características gerais que compõem a obra, incluindo as relações entre os internos, o espaço habitado e a ausência de comprometimento afetivo entre os hóspedes da casa, circunstâncias que geram estados de convivência estressantes e emocionalmente exaustivos:

\begin{abstract}
Alguns [personagens] urinam em qualquer parte, outros babam, outros gritam, outros entopem os banheiros. Ida é tomada como objeto de desejo de Arsenio, que abusa dela permanentemente. Os corpos estão tão lastimados como suas mentes, que não têm noção de justiça nem vontade para mudar nada. O protagonista estabelecerá diferentes relações com seus companheiros de asilo, ainda que em nenhuma delas manifeste qualquer tipo de compromisso afetivo. As relações lhe permitem apenas conhecer os personagens e narrá-los. Há uma espécie de inquietação no narrador-personagem em conhecer, sem esforço, somente através da observação, esses "fugitivos", que se parecem tanto e, ao mesmo tempo, tão pouco com ele (ESCOBAR, 2009, p. 54, tradução nossa $)^{30}$.
\end{abstract}

De fato, na boarding home os hóspedes não estabelecem relações de confiança entre si. O clima da casa não oferece condições para o desenvolvimento do cuidado, do amor ou da empatia, tampouco de qualquer harmonia entre os moradores. Cada "companheiro" constitui uma ameaça em potencial, um risco iminente à integridade física e material dos internos, motivo pelo qual estes tendem ao isolamento social e a ataques recíprocos. O sentido de lealdade é corrompido; qualquer mostra de solidariedade permanece suspensa pela hostilidade que o ambiente impõe. Quando compreende a dinâmica do lugar, William, inspirado nas ações de Arsenio, também passa a roubar os outros hóspedes - dinheiro, cigarros, miudezas. Arsenio, por sua vez, vale-se da confiança depositada pelo sr. Curbelo, a ponto de sentir-se protegido por todos os excessos que comete contra os loucos. Suas arbitrariedades e condutas obscenas são compensadas pela "dedicação exclusiva" do encarregado ao trabalho no manicômio: "Pela primeira vez na vida, Arsenio se sente completo em um lugar. Além disso, sabe que Curbelo nunca o despedirá. 'Eu sou tudo para ele', costuma exclamar. 'Nunca encontrará outro como eu' ${ }^{31}$ (ROSALES, 2003, p. 23-24, tradução nossa). A mulata Caridad, igualmente, beneficia-se da omissão de Curbelo, ao afanar parte dos alimentos destinados aos loucos para alimentar seus cães. E se os protestos chegam ao proprietário do estabelecimento, Curbelo contesta: 'Esses empregados gozam da minha absoluta confiança. Logo, nada disso é verdade'. "E os loucos perdem outra vez, e compreendem que aqui o melhor é calar"32 (ROSALES, 2003, p. 41, tradução nossa).

30 "Algunos [personajes] orinan en cualquier parte, otros babean, otros gritan, otros tapan los inodoros. Ida es tomada como el objeto de deseo de Arsenio, quien abusa de ella permanentemente. Los cuerpos están tan lastimados como sus mentes que no tienen noción de justicia ni voluntad para cambiar nada. El protagonista establecerá diferentes relaciones con sus compañeros de casa aunque en ninguna manifiesta un compromiso afectivo ni de ningún tipo. Las relaciones sólo le permiten conocer a los personajes y narrarlos. Hay una especie de inquietud en el personaje narrador para conocer, sin esfuerzos, sólo a través de la observación, a estos "huidos" que se parecen tanto y, a la vez, tan poco a él."

31 "Por primera vez en su vida Arsenio se siente completo en un lugar. Además, sabe que Curbelo nunca lo botará. 'Yo soy todo para él', suele exclamar. 'Nunca encontrará a outro como yo.'”

32 'Esos empleados gozan de mi absoluta confianza. Así que nada de eso es verdad'. 'Y los locos pierden otra vez, y comprenden que aquí lo mejor es callar".

Revista do GELNE, Natal/RN, Vol. 23 - Número 1: p. 83-98. Fevereiro. 2021 
A fragilidade dos laços afetivos, a insegurança e a dificuldade de se constituir níveis mínimos de sociabilidade tendem a desenvolver nos internos, segundo Goffman, um sentido aguçado de preservação pessoal, que pode se manifestar em ações vitimizadas ou discursos autocomplacentes. Há ressonâncias desse processo no romance, embora a apatia seja a resposta defensiva mais evidente na estrutura mental dos personagens, reproduzida pelos comportamentos inexpressivos descritos ao longo da narrativa.

Por fim, menciona-se a grande dificuldade de readaptação que os internos sofrem ao romperem com a vida formalmente administrada das instituições totais. Em geral, quando o interno é reenviado à sociedade, o processo de reaprendizagem social mostra-se doloroso e permeado por traumas. Mortificado em sua estrutura física e mental, o indivíduo sente a angústia da libertação por acreditar-se incapaz de se readaptar novamente à vida doméstica, a ponto de muitas vezes expressar desejo em retornar à instituição que antes o abrigava. Segundo Goffman (1987, p. 67) “(...) talvez essa perspectiva seja desmoralizante, e seja uma das razões para que os ex-internados frequentemente pensem na possibilidade de voltar [às instituições totais], bem como uma razão para que um número apreciável faça exatamente isso". Nesse sentido, são comuns, nos relatos de egressos dessas instituições, sentimentos de indiferença ou apatia em relação à própria libertação.

A situação de William reproduz a indiferença do personagem em relação a qualquer possibilidade de mudança: por mais que em certo momento deseje reconstruir sua liberdade ao lado de Francis, à procura de um lar para os dois, no fim do romance, ao ter seus projetos frustrados, o personagem toma consciência da própria impotência diante da estrutura que o aniquila. Sua esperança de um novo destino é sequestrada pelas condições impostas, tanto no exílio, quanto no estado de reclusão perpetrado. Mergulhado na solidão, negligência e insignificância, o protagonista passa a reproduzir sem remissão o ciclo da insanidade e do desespero da home, imprimindo nos corpos dos outros loucos as marcas dos abusos físicos que a estrutura institucional lhe impõe, pouco afeta ao acolhimento e cuidado humanos.

William Figueras não é simplesmente vítima de um sistema que o aprisiona e o desmoraliza. Aos poucos, também assume a tirania do espaço e toma para si o complexo de violações às quais está sujeito: incorpora a barbárie e apropria-se dela, ao reproduzir a hostilidade e crueldade contra os demais internos. Redireciona os insultos, encarna as ofensas, personifica a cólera. Sua agressividade não mais repousa perante os seus ofensores, mas também em face dos que vivenciam as mesmas circunstâncias de humilhação e desumanização do manicômio. Tornase, no fim das contas, a reificação de seu próprio antagonista.

William Figueras converte-se em boarding home.

\section{CONSIDERAÇÕES FINAIS}

Este artigo concentrou-se em examinar as aplicações e os efeitos dos mecanismos desumanizadores em indivíduos submetidos à disciplina de instituições manicomiais, tomando como referência o romance Boarding Home (2003), do escritor cubano Guillermo Rosales.

A partir dos conceitos mortificantes extraídos da obra Manicômios, prisões e conventos (1987), de Erving Goffman, foi possível refletir sobre uma série de processos que reverberam sobre as relações de desmembramento identitário e morte civil, especialmente seus reflexos nas dimensões intersubjetivas dos grupos de internados. Nesse sentido, buscou-se examinar de que forma os processos profanadores agem sobre a estrutura do eu, discutindo-se os instrumentos de dominação aplicados nos contextos das instituições totais em consonância ao desenvolvimento da narrativa de Rosales.

A boarding bome representa um fracasso definitivo enquanto casa de acolhimento: trata-se de um lugar insalubre, permeado pelo descaso, pela violência e pela miséria. Lugar de violação e descompromisso com a vida dos internos. William Figueras, embora incapaz de alterar seu 
destino, tem consciência disso: "Bem. Este é o meu fim. O último ponto a que pude chegar. Depois desta boarding home não há mais nada. A rua e nada mais" (ROSALES, 2003, p. 20, tradução nossa) $)^{33}$.

O escritor cubano Guillermo Rosales, a partir de sua própria experiência com o hospício e com a loucura, produziu um poderoso relato sobre a opressão manicomial e suas consequências na vida dos indivíduos que sofrem esse tipo de coerção. Indivíduos que a cada dia perdem completamente a noção de quem são, do que representam e de que papéis sociais devem assumir. Boarding home é, antes de tudo, a negação dos valores de seu tempo, do espaço habitado e do mundo que o rodeia. Uma mensagem pessimista de abandono, solidão e desesperança.

\section{REFERÊNCIAS BIBLIOGRÁFICAS}

ABREU, Juan. Pequeño elogio de la escoria. Homenaje a Mariel. Revista Encuentro de la Cultura Cubana, $\mathrm{n}^{\circ}$ 8/9, primavera/verão de 1998, p. 135-138. Disponível em: https://www.cubaencuentro.com/var/cubaencuentro.com/storage/original/application/d789e3 9ce92f389b03345b4c519770fa.pdf Acesso em 01 set. 2020.

DOSSIEE de Guillermo Rosales. Conjunto de publicações reunidas sobre o escritor. Disponível em: https://incubadorista.files.wordpress.com/2012/06/ros.pdf Acessado em: 20 jul. 2019.

ESCOBAR, Mariela Alejandra. Guillermo Rosales: Por los bordes de los márgenes. Congreso de la Asociación de Estudios Latinoamericanos, 11-14 jun. 2009, Rio de Janeiro. Disponível em: https://incubadorista.files.wordpress.com/2012/06/ros.pdf Acesso em 17 jul. 2020.

FELIPPE, José Abreu. Guillermo Rosales, la soledad y la cólera. Revista Cacharro(s), La Habana, $\mathrm{n}^{\circ}$ 08-09, enero-junio de 2005, p. 16-17. Disponível em: https://incubadorista.files.wordpress.com/2010/11/cacharro s 8 9.pdf Acesso em 18 jul. 2019. GOFFMAN, Erving (1961). Manicômios, Prisões e Conventos. Tradução de Dante Moreira Leite. $2^{a}$ ed. São Paulo: Editora Perspectiva, 1987 (Coleção Debates).

LEYVA MARTÍNEZ, Ivette. Guillermo Rosales o la cólera intelectual. Revista Encuentro de la Cultura Cubana, Madrid, n 26/27, p. 98-108, otoño-invierno, 2002-2003. Disponível em: https://www.cubaencuentro.com/var/cubaencuentro.com/storage/original/application/141eba 74dd08eb8a2ff60e6b5b89ee28.pdf Acesso em 12 jul. 2019.

LEYVA MARTÍNEZ, Ivette. El azaroso destino de E1 alambique mágico. Revista Encuentro de la Cultura Cubana, Madrid, n 47, p. 47-48, invierno 2007-2008. Disponível em: https://www.cubaencuentro.com/var/cubaencuentro.com/storage/original/application/4d048a dc6df0a22367e8d5fc18fbadbe.pdf Acesso em 13 jul. 2019.

LÓPEZ, Armando. El testamento de Guillermo Rosales. Nova York: CubaEncuentro, 2009. Disponível em: https://www.cubaencuentro.com/cultura/noticias/el-testamento-de-guillermorosales-180438 Acesso em 01 set. 2020.

ROSALES, Guillermo. Boarding Home (La casa de los náufragos). Madrid: Ediciones Siruela, 2003.

33 “Bien. Éste es mi final. El último punto a donde pude llegar. Después de este boarding home ya no hay más nada. La calle y nada más". 
TUAN, Yi-Fu. Paisagens do medo. Tradução de Lívia de Oliveira. São Paulo: Editora UNESP, 2005.

VELAZCO, Carlos. Si nos llamáramos Guillermo Rosales (una obra frente a la intemperie insular. In: Revista Conexos, vol. 03, otoño 2015. Disponível em: https://conexos.org/2015/07/26/si-nos-llamaramos-guillermo-rosales-una-obra-frente-a-laintemperie-insular/ Acesso em 20 jul. 2019.

Submetido em $09 / 12 / 2020$

Aceito em 11/02/2021 